\title{
Towards the very nature of corporate strategy
}

\author{
D. Heil, T. Maxwell and L. Whittaker* \\ Wits Business School, 2 St Davids Place, Parktown 2193, \\ Republic of South Africa \\ whittaker.L@wbs.wits.ac.za
}

Received March 2003

\begin{abstract}
Current approaches to corporate strategy are overwhelmingly based on a metaphorical - and mostly unarticulated understanding of the essential nature of corporations. In this paper we argue that in order to understand corporate strategy it is critical to understand the very nature of the entity called 'corporation'. We then present an understanding of corporations as works; those entities that create and sustain the world in which humans live. In describing the characteristics of works and the way in which they create and sustain a world, we elucidate the very nature of corporate strategy. We conclude by proposing a process to enable leaders of corporations to engage in corporate strategy as creating and sustaining a world.
\end{abstract}

*To whom all correspondence should be addressed.

\section{What is corporate strategy?}

Most corporations today have some sort of corporate strategy. Most MBA programmes are centred around a course in strategic management. The literature on strategic management is 'vast, and... growing at an astonishing rate' (Mintzberg et al., 1998:18). And yet there is no single consensus on what corporate strategy actually is. Mintzberg (1987), for example, provides five definitions of strategy and ten schools of strategic management thought (Mintzberg et al., 1998), all of which are sourced in the vast strategic management literature. At the same time it is noted (Mintzberg, 1998:20) that:

Pervasive strategic failure in many large corporations may well be attributed to the army of business school graduates who have been sent out with an incomplete toolkit.

Thus is seems that, in order to act effectively, managers must hold in mind a number (ten or more) of competing interpretations of what strategy is, and how to execute it.

In this paper, we address the question 'What is corporate strategy?' In order to do so, we take a step back and ask a question that we consider to be more basic, or primordial; that we believe can lead to a better understanding of corporate strategy - one that can take into account 10 or more schools of thought, but hold in mind a singular underlying logic. That question is: 'what is a corporation?'

We believe that this question is primordial, because it asks a 'prior', or ontological question. To ask 'what is a corporation?' is to question the very nature of the entity, corporation. Strikingly, this is not a question which is addressed in the strategic management literature per se. ${ }^{1)}$ In Mintzberg's comprehensive review of the field of strategy, there is in fact no definition of the corporation, and the word as such does not appear in the index, except as a related adjective ('organizational'). Only once, briefly, does he point out that some branches of the cultural school see the organization $^{2)}$ as culture (Mintzberg et al., 1998:270), but it is quite clear that culture is more generally seen as an explanatory framework for strategy, rather than for the organization itself.

This more primordial question is a useful one, not just because it occurs logically prior to thinking about corporate strategy (how strategically to manage the corporation), but because, without it, managers operate without an explicit understanding of that which they are trying to manage. It may of course be argued that the nature of the corporation is implicitly understood by the men and women who create

\footnotetext{
${ }^{1)}$ In raising this question, we are further aware that we are tangentially engaging with a considerable body of organization theory, that provides a number of perspectives on how we can think about organizations, such as social constructionism (Fairclough, 1995; Van Dijk, 1997), structuration theory (Giddens, 1984), discourse theory (Grant \& Oswick, 1998), and metaphorical analysis (Morgan, 1986). We would contend, however, that none of these perspectives directly asks the ontological question, 'what is a corporation?'. Social constructionism, for example, discusses how individuals socially construct their realities, while structuration theory asks what it is that holds social structures together over time. Discourse theory analyses organizational structures, processes and practices, while metaphorical analysis provides various ways of thinking about the organization. All of these are very insightful ways of thinking about various aspects of organizations, as multi-dimensional constructs. It is our aim, rather, to provide a unified understanding of what a corporation actually is.

${ }^{2)}$ Where necessary, we have used the words 'corporation' and 'organisation' interchangeably, on the basic premise that we refer always to corporate organisations (rather than societies, movements or religions for example).
} 
and manage it; that this is a sort of tacit knowledge (Polanyi, 1969) essential to the successful management of corporations. Certainly the history of the open market economy abounds with cases of extraordinary leaders who created equally extraordinary corporations: Siemens, Coca Cola, Ford Motor Corporation, Disney, Boeing, Sony, Microsoft and De Beers, to name but a few.

The tacit nature of this knowledge however, means that, unless this question is asked, the understanding of what a corporation is cannot be surfaced in a meaningful way. Consequently an understanding of how to create similar successes (to succeed at corporate strategy) cannot be articulated except in a fragmented, and from a prescriptive point of view, inadequate, way ${ }^{3)}$.

It could also be argued that it is unnecessary to achieve a unified understanding of what a corporation actually is, that this is a reductionist, and perhaps misguided aim. As a starting point in our argument, therefore, we address a less reductionist and better researched means of understanding corporations without reducing them to their essence - that of the metaphor. We show why metaphors are useful, but ultimately inadequate, in understanding and managing corporations, and thus why we need to answer the question, 'what is the corporation?' We then, using Heidegger's typology of entities, directly address this question, and suggest that the corporation is of the type of entity, a work. We conclude by addressing the implications for corporate strategy of this assertion, 'a corporation is a work'.

\section{Metaphors used to understand corporations}

In asking the question about the very nature of this entity called 'the corporation' we might well revert to the use of metaphors that have informed strategic thought and that have been applied to corporations in business press and in the minds of business leaders for many years. Metaphor 'the application of name or descriptive term to an object to which it is not literally applicable' (Fowler \& Fowler, 1964:763) - is generally a helpful practice in broadening human understanding of a phenomenon that is not readily understood at the outset, by 'prefigur[ing] the ground to be studied' (Morgan, 1983:603). As Morgan further points out 'organisation' is in itself a metaphor, rather than a literal reality, and 'it is the realization that organizations are not organized to the extent that the metaphor 'organization' suggests they should be, that provides an impetus for their conceptualisation in other terms' (Morgan, 1983:603).

Consider the following examples drawn from The Economist articles:

- 'The age of web services actually began several years ago, but only experts noticed because it happened deep down in the companies' plumbing', (The Economist, 2001a:2);

\footnotetext{
${ }^{3)}$ Kiechel suggests that less than $10 \%$ of formal corporate strategies are ever implemented in any form at all (Kiechel, 1984:4 cited in Mintzberg et al., 1998:177).
}

- $\quad$ 'That hardy workhorse of capitalism - the joint stock company...', (The Economist, 2001b:1);

- 'The corporation is the 'master', the employee is the 'servant'...', (The Economist, 2001c:1).

In the first example, the corporation is referred to as a building by implying that web services constituted the building plumbing. Many would understand that the essential function performed by plumbing is hidden until a blockage is experienced. The metaphor makes of the corporation a construction - a physical object - to enhance communication of a valuable truism.

The second metaphor makes of the corporation a workhorse, and infers other properties of an animal on the corporation. The image is one of an entity that exists to do its master's will, that has been tamed to ask nothing in return for its work, and that requires only food, water and occasional rest for it to perform optimally.

The third metaphor suggests that corporations are human; that they are capable of observing other entities in their environment, and directing them through a process of cognition and interpretation about that environment. This kind of corporation must have a brain, and a set of attitudes and beliefs that can be altered by observation and learning.

In all three cases corporation is assumed to be something: an object, an organism or a human. It is not intended, necessarily, that the metaphor should hold under all circumstances - this is made apparent by the fact that frequently a number of metaphors are used with reference to the same corporation. In other words, the tacit answer to the question 'what is a corporation?' is not meant to be accepted comprehensively (or reductively) when a metaphor is applied to a corporation.

Nonetheless, these metaphors, used frequently enough, can acquire the status of fact, although in an implied and assumed rather than explicit way, becoming dormant metaphors 'through which we restrict ourselves to seeing the world in particular ways' (Tsoukas, 1991:569). For example, scientific thinking tends to suggest the notion that the corporation is a physical object, since these are the kinds of entities for which the methodologies of scientific research are most applicable. The metaphor of the machine (Morgan, 1986), therefore leads managers to assume that the corporation is in fact a physical object, or at least that it will behave like one. Probably the most prominent scholars in this line of thought, which is also referred to as Fordism, are Taylor (1911) and Fayol (1949). Such thinking was dominant for most of the $20^{\text {th }}$ century, both in capitalist and communist countries (Morgan, 1986:25).

The machine metaphor has served to gain advantages under reasonably straightforward, stable and simple conditions, however it has also caused serious damage. 'In understanding organization as a rational, technical process, mechanical imagery tends to underplay the human aspects of organization and to overlook the fact that the tasks facing organizations are often much more complex, uncertain, and difficult than those that can be performed by most machines' 
(Morgan, 1986:27). The machine metaphor treats people as parts that have to fit into the machine. Consequently humans are regarded as physical objects and thus are denied their very nature. Furthermore, the information and knowledge age sees the rising prominence of corporations that display minimal physical manifestation in the traditional form. While most corporations still have a significant physical expression like manufacturing facilities or buildings, it is not appropriate to consider corporations as being physical objects. It is thus legitimate to say that a corporation is not a physical object and that even using this notion in a metaphorical sense can be problematic.

The organism metaphor, of course, is intuitively more appealing than the object metaphor. Applying the metaphor of the organism to the corporation is already visible in the etymology of the word. 'Corporation' is derived from the Latin word 'corpus,' which means body, implying that this type of community is in fact an organism. Like "organisation", corporation is in fact a dead metaphor in which the literal meaning has become identical with the former metaphorical meaning. Dead metaphors however "by themselves cannot provide significant insights regarding the study of specific phenomena", and the use of living or explicitly descriptive metaphors becomes necessary (Tsoukas, 1991:569). A number of scholars have thus contemplated metaphors for the corporation of organisms, organs or collectives of organisms. This view found expression in open systems theory (Beer, 1980; Katz \& Kahn, 1978; Kast \& Rosenzweig, 1973), applied theories from population ecology (Hannan \& Freeman, 1977), organisational ecology (Astley, 1984), various applications of cybernetics (Senge, 1990), the notion of autopoiesis (Luhmann, 1995; Ulrich \& Probst, 1984; Von Grogh \& Roos, 1995), much of what complexity theory (Wheatley, 1992; Stacey, 1992) contributes to organisational theory, and much of what Mintzberg et al. (1998) characterize as the environmental school of strategy.

It seems obvious that these metaphors are richer than the machine metaphor, since a corporation does react to a stimulus in its environment. This reaction to a stimulus is not of the same nature as that of physical objects, but is more accurately described by comparing it to the reaction of an organism. According to Heidegger (1993a) organisms live in a dazed ${ }^{4)}$ relationship to their environment. While one

\footnotetext{
${ }^{4)}$ It is easily observable that animals and plants react to circumstances to which stones, due to their nature, could not react. In their own way animals do relate to their environment. However, it takes a lot of methodological care to determine what is meant by the word 'relate' in this context. According to Heidegger animals do not have world, 'but they belong to the covert throng of a surrounding into which they are linked' (Heidegger, 1993:170). Animals live in a surrounding (which in biology is called 'habitat') because it surrounds them in quite a fixed, particular and rather predetermined way. Heidegger calls this relation 'dazed' (Heidegger, 1992:344), regardless of the sensory superiority of some animals. The animal is linked, rather than open to, the content and multiple references of the environment and is characterised as 'world-poor.' There is a certain richness of interpreting and learning that is not available to animals due to their very nature. Humans can empathize with animals and, to a certain degree, even with plants, because animals and plants relate to their environment and humans, animals and plants share features that come with integrally being an organism.
}

might argue that most corporations relate to their surroundings in a rather 'dazed way', seeing it mostly in terms of established categories like market opportunities and competition, there are corporations that have fundamentally altered their identity and subsequently their interpretation of a situation in a way unfathomable to a non-human organism like a plant or animal. It seems that this ability to change their own understanding and identity is a key feature for corporations that survive and thrive for long periods of time (De Geus, 1997), and that the view of corporations as organisms is only partially applicable.

A further objection to stating that corporations are organisms is that they do not have a body in the biological sense. Thus, it is clear that while the metaphor of corporation as organism is an improvement on corporation as physical object, corporations are not organisms, and this way of viewing corporations must remain metaphorical.

The view of the organisation as human forms the premise of the learning school of strategy, which is itself based in the organisational learning literature. Organisational theorists have given the corporation human characteristics, which are expressed in words like organisational memory, organisational knowledge, organisational learning, and organisational or collective mind (Jones, 1995).

What seems to be the case is that in the public discourse specific humans are seen as what defines a corporation (Mintzberg et al., 1998:131). Thus, for example, Richard Branson personifies Virgin Atlantic, even though it is obvious that a corporation is much more than the top manager or founder. This way of thinking might stem from the familiarity of humans with themselves and the difficulty of Cartesian thought to fathom the corporation as an entity beyond the notion of an accumulation of physical entities, organisms and humans. Since corporations are a form of human community, it is understandable that it is often difficult to distinguish between the corporation and the individual. When for example, a corporation notifies the public about an issue, this is done through and by one or more individuals. However, since the corporation is not just one individual human and does not have a biological body, it is clear that the corporation is not the same type of entity as a human being and that to regard corporations as human beings therefore must remain metaphorical.

\section{The limitations of object, organism and human metaphors}

It is apparent that object, organism or human metaphors are limited to being only metaphors. It could however be argued that these metaphors are appropriate exactly because the organization cannot be reduced to any one of them. One could describe a corporation with the aid of a variety of metaphors under a variety of different conditions, each time achieving the desired learning. Morgan argues, for example that, fundamentally, 'different schools of thought in social science ... are based upon the acceptance and use of different kinds of metaphor as a foundation for enquiry', and that the challenge is thus to 'appreciate a variety of metaphors ... through which theory and research can be conducted' (Morgan, 1980:607). 
There are two problems with this argument for those involved in corporate strategy: Firstly it assumes that managers know that they are using metaphors. However, as Tsoukas (1991) points out, many metaphors are dormant or even dead, and thus managers (and in many cases, theorists and researchers) are unaware that they are using them.

Secondly it assumes that managers can skilfully select the appropriate metaphor to guide their actions through a specific set of leadership or management challenges. Since the metaphors themselves are strongly paradigmatic - that is, rooted in alternative realities - they could have radically different implications for the management and strategic guidance of organisations. Morgan (1980) demonstrates how different epistemological and ontological assumptions (which we all hold, whether we are aware of them or not) give rise to different paradigms, or ways of thinking about organisations. Figure 1 shows how different metaphors might gain currency in different paradigms, and thus how insights associated with different metaphors might guide the manager.

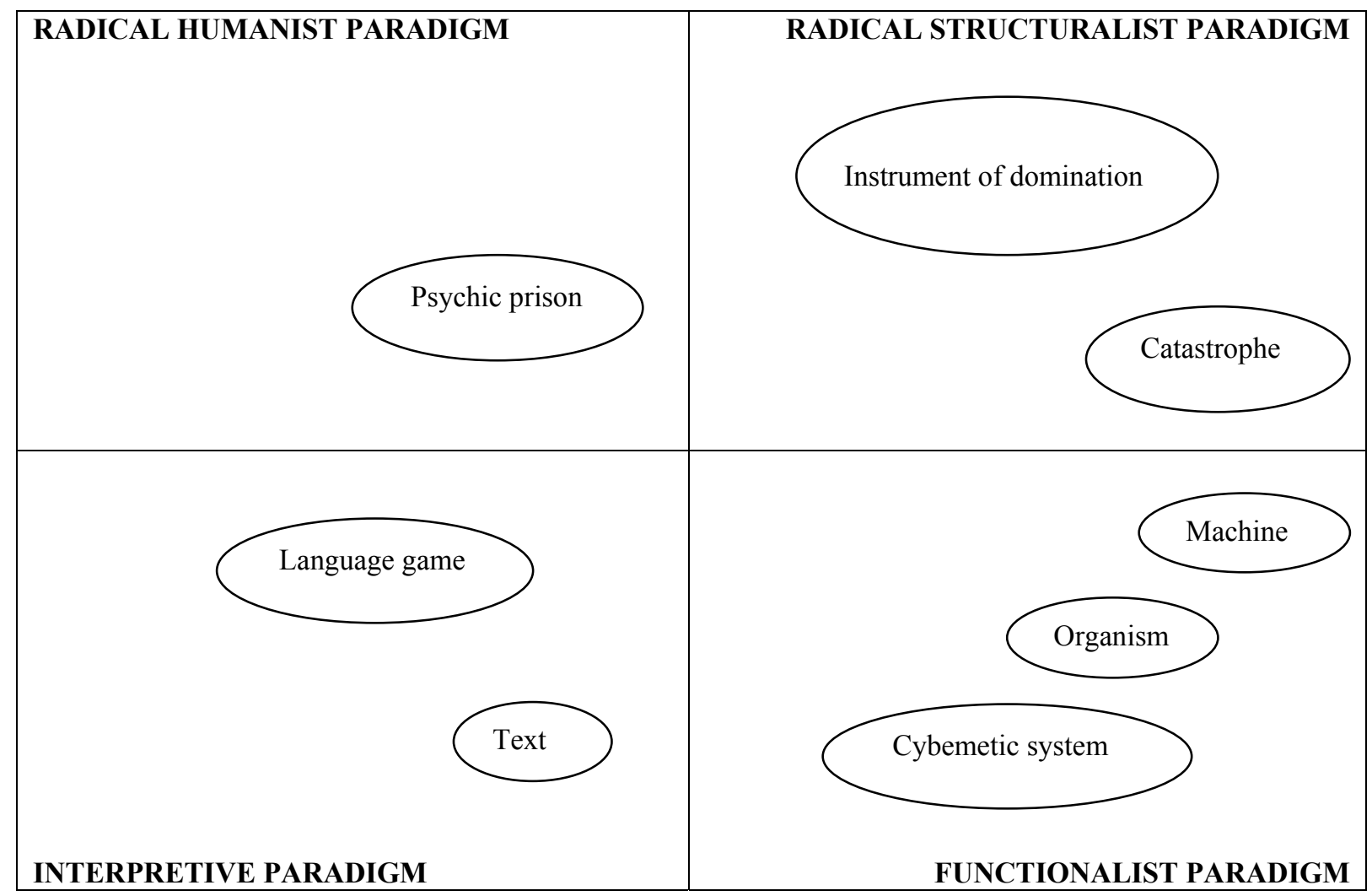

Figure 1: Paradigms and selected metaphors of organisations Source: Adapted from Morgan (1980)

For example, the machine and organism metaphors are strongly associated with the functionalist paradigm ${ }^{5}$. Thus a manager who sees the corporation as a machine or organism will expect that employees, given certain direction or constraints, will necessarily act in a certain, predeterminable and rational way (notwithstanding the fact that employees might well object to being treated as pipes in a cistern, or workhorses in a field). Those managers who view

\footnotetext{
${ }^{5)}$ It is beyond the scope of this paper to discuss the paradigms in detail. For purposes of clarification however, it can be noted that 'the functionalist paradigm is based upon the assumption that society has concrete, real existence and a systematic character', while the interpretive paradigm is based upon the view that 'what passes as social reality does not exist in any concrete sense, but is the product of the subjective and inter-subjective experience of individuals'. The radical humanist paradigm ties the analysis of a socially created reality to 'the pathology of consciousness, by which human beings become imprisoned within the bounds of [their] reality' and the radical structuralist paradigm 'is predicated upon a view of society as a potentially dominating force... tied to a material conception of the social world' (Morgan, 1980:608-609).
}

the corporation as a psychic prison or an 'iron cage' (Weber, 1978), on the other hand, will expect employees to be alienated and 'subservient to the artificially contrived and reified needs of modern organization' (Morgan, 1980:618), and therefore capable of acting in politically-determined and apparently irrational ways.

The selection of the governing metaphor is determined by the manager's philosophical predisposition. To a selfdeclared interpretivist, for example, it is clear that much of what constitutes the organisation is actually a language game. Yet it is equally obvious that the organisation cannot only be a language game, given that it does have some sort of physical manifestation, some of sort of network of power, and so on. Metaphors at best add a rich and creative dimension to thinking about the organisation, but they do not address the fundamental nature of organisations.

The idea that metaphors might be misleading is by no means original. Pinder and Bourgeois (1982), for example, suggest 
that the use of tropes (including metaphors) may 'impede the development of ... a body of knowledge useful to practitioners' (Morgan, 1983:601). This, they suggest, is because the use of metaphor prevents the development of 'sufficient precise literal language for stating hypotheses and formal theories as carefully as we would like' (Pinder \& Bourgeois, 1982:612). Thus what they seek, in contrast, is operational definitions, and an analytic taxonomy to describe accurately the features and attendant appropriate actions for particular kinds of corporations.

Such a suggestion, it may be argued, is itself using the dead metaphor of the corporation (corpus) in a strongly biological sense, suggesting as it does, taxonomy and classification. And as Morgan points out 'much contingency theory is based on the organism metaphor of the corporation - the living entity better able to survive in some environments than in others' (Morgan, 1980:614). More fundamentally, Pinder and Bourgois's (1982) view suggests that we can escape metaphor completely, at least in analysis, whereas Morgan argues that structuralist linguistics has shown that tropes (metaphors among them) are 'the axes on which human experience builds' (Morgan, 1983:602).

It is therefore not our suggestion here that metaphors must be entirely abandoned in thinking about the corporation and its strategy. We concur with Morgan (1983) in his constructivist approach to language. Furthermore, we hold that Pinder and Bourgois's (1982) suggestion that understanding the nature of the corporation can proceed 'bottom up' from operational definitions, aside from its underlying organismic metaphor, will not necessarily yield a good non-contingent understanding of the corporation. As Heidegger tells us 'obviously a thing is not merely an aggregate of traits, nor an accumulation of properties by which that aggregate arises. A thing ... is that around which the properties have assembled' (Heidegger, 1993b:148, emphasis added).

Rather, our objective here is to achieve a good, noncontingent understanding of the essential nature of the corporation - that around which the operational aspects are assembled. We are suggesting that if the actions available to a manager can be altered by the way in which she understands corporation - her governing metaphor - then so too could the effectiveness of corporate strategy be hindered by any particular (and therefore partial) understanding of the corporation. We propose that a better understanding of the essential nature of a corporation is gained by thinking of the corporation not metaphorically, or in terms of its constituent parts or operational characteristics, but as a particular kind of entity. Objects, organisms and humans are all kinds of entities, which we compare metaphorically to the corporation. But the corporation itself actually is, we propose, the kind of entity that can be called a Work.

\section{The corporation as a work}

There are entities that we encounter that do not, or do not primarily exist as a physical manifestation, and yet which are real in the human experience. Examples would be symphonies, Newton's or Einstein's laws of physics, nation states or poetry. Heidegger (1993b) refers to these as 'works'. According to Heidegger works set up and produce a world. World here does not refer to all objects in the external environment or universe as it would be in the Cartesian tradition, but is used in a similar way as that which for example allows for 'the world of a mathematician' and then means 'the realm of possible mathematical objects' (Heidegger, 1962:93) or the 'corporate world', which refers to the realm of possible objects and issues concerning or relating to the corporation.

However, more generally, it is world which permits for the possibility for 'a world' to be there in the first instance. World means the always already familiar horizon upon which everyday human existence moves with absolute confidence and within which humans make sense out of both their environment and themselves. World is the ultimate reference which cannot be explained by any other reference and can thus not be determined via explanation ${ }^{6}$. In Heideggarian terms, world is the referential whole in which practices and entities have meaning at all. World allows for the possibility of explanation itself in the first instance. The references within the whole sustain meaning in the context of the particular world, because they relate to each other, by showing up as something within the world. For example, a hammer can be seen to be a hammer because it is used to drive a nail, for the purposes of carpentry, for the purposes of creating chairs on which we sit, and tables at which we eat. Without the practice of sitting at table, what would the hammer be? ${ }^{7}$ )

What a work does is to reveal the world, thereby making it possible for references to show up for humans, as they are experienced by humans. For example, a rose in bloom is experienced by many humans as a thing of beauty, but by a farmer (in the commercial flower industry) as a source of income, or by a chemist (in the world of perfumery) as a source of a chemical compound. For the layman a hammer is a hammer, for the carpenter each hammer is of a particular kind. Importantly, for humans, everything shows up as something, depending on the particular world in which one is. And what things show up as, is what we would call actuality, or truth. Thus, as a work sets up and produces a world it is also that which 'truth establishes itself in' (Heidegger, 1993a:187). A work can be said to 'work when it worlds'.

To explain the notion of the entity called 'a work' Polt uses the Vietnam Veterans Memorial in Washington, designed by Maya Lin, and usually referred to as 'the Wall' (Polt, 1999:135-6). The memorial is a simple V-shaped trench made of a series of black stone sheets inscribed with the

\footnotetext{
${ }^{6)}$ Humans will never be able to actually experience or fully articulate this understanding that is critical to encountering anything in the way in which it is encountered. Since world cannot be explained, yet is fundamental to being human, it remains the essential mystery of human existence that distinguishes humans from all other entities.

${ }^{7)}$ Obviously this is a hugely simplified example - we use hammers for a multitude of purposes, but this is exactly the point, that it is all the practices and entities in the referential whole, that refer to each other, and give each other meaning, within a particular world. The world of the San people, for example, as a nomadic hunter-gather world, might be expected to have no concept of a hammer, as a construction tool, as we know it.
} 
names of all the American soldiers who lost their lives in the war. It has become a sacred site both in and beyond the United States. That which makes it a work of art cannot be found in the material of which it is made nor in its beauty or aesthetic appeal, but in its effect of creating a world, by establishing truth for many people, or in Heidegger's terminology, unconcealing a reality. The Wall makes the Vietnam War present, and establishes and preserves this event as a fundamental dimension of American identity, regardless of the political conviction of the visitor to this work of art. Such revelations belong to every work. Works, by creating a particular world, determine that which is important: 'By the opening up of a world, all things gain their lingering and hastening, their remoteness and nearness, their scope and limits' (Heidegger, 1993a:170). The world and the truth (that which is important, that which shows up at all) that are created by genuine and original works are never arbitrary. They are always responding to a historical situation, and they bring forth the very nature of the entities that exist in that world.

Given Heidegger's typology of entities (physical object, organism, human and work) it is suggested here that the essential nature of the corporation is that it is a work, which in a distinct way sets up that background called world, within which humans make sense out of situations. By suggesting that the corporation is a work, we are suggesting that it is the essential nature of the corporation that it sets up and sustains a particular world.

This is quite distinct from saying, for example that the corporation interacts with its environment, as the environmental, and to a certain extent, the positioning schools of strategy suggest (Mintzberg et al., 1998). The notion of an external environment presupposes that there is already world. Instead, we see that 'the world is not a mere collection of countable or uncountable, familiar and unfamiliar things that are at hand. But neither is it a merely imagined framework added by our representation to the sum of such given things... World is never an object that stands before us and can be seen.' (Heidegger, 1993a: 170). World is what gives reference and allows for something to show up at all. Thus, a corporation (as a work) sets up a world, a realm of possibilities for action. Whereas the business world is the totality of references that are the conditions of possibility for us to be business people (i.e. economic transactions, markets, buyers, sellers, suppliers, banks, money, shops, marketing, etc.), in any particular corporation there are particular conditions of possibility which apply. A corporation in which customers show up as customers, and furthermore as important, for example, is probably in a competitive business, rather than a monopolistic enterprise.

\section{Is 'work' another good metaphor?}

Is a work another good metaphor for what a corporation actually is? Or could it be said that a corporation is a work? Corporations are indeed created by individuals or teams of people. They do express the inspiration of their creators, they are frequently nurtured or sustained by people other than their original creators, and most importantly, they do set up the world - the realm of possibilities for action - for many people associated with them. As an illustration of this, one might think of Apple, Shell, Nokia, Virgin, or The Body Shop. The names of these corporations are evocative. They conjure up images in our minds, and spark responses. The way in which they impact on our lives - through their products and services, through their ethos or their management style - is definitive. It creates the world in which we live; different for each one of us, but definitive nonetheless. Such works are no less definitive than our national anthems, or Monet paintings. Often they are more definitive. Think of Enron or Worldcom. These too are works, but if our responses to these companies are different to those mentioned earlier, it is because the way in which they define our worlds is different.

We would suggest that 'work' is exactly not a metaphor for the organisation, but an ontological, essential definition of what the organisation always already is. The organisation is always a work, because it always reveals a world, whether we relate to that world or not. The corporation is a work because it worlds. It brings into being certain possibilities, certain references, and excludes others. The corporation always sustains certain meanings, by revealing a certain world. Everything in the organisation shows up as something, within a world. That we live and move and work in organisations is exactly because they reveal a world. When our functioning within the organisation breaks down it is because the nature of that world is unclear, not because the strategy or the direction are unclear, but because the very world, the horizon on which we understand and act, is unclear. We don't know what things are, because they do not show up as themselves, in the world.

Of course, corporations are generally not explicitly understood by managers to be works. Metaphors of objects, machinery and organisms have abounded in management since the industrial age. Metaphors linking corporations to other works are also used, though without recognition of the fact that a corporation is itself a work. So a factory may be operated with ' 40 hands on each line', or a company run with the sole objective of improving simple profit formulae (i.e. governed by machine metaphors), and yet, bizarrely, presented to the public as works (world-creating), through marketing campaigns that seek to convince the consumer how sincere/ethical/eco-friendly they are. Corporations pretend to be works, because their market research has demonstrated that clients want to interact with works that represent a reality that accords with their own way of living, their own understanding of the world, their own search for meaning. The corporation often pretends to be a work because it does not know that it is a work!

It is our contention however, that the corporation always is some kind of a work. Corporations create a world for people - they set up a realm of possibilities for action that may or may not bring forth the best in them. It is not primarily the corporation's physical expressions that do this - the 'mere collection of countable or uncountable, familiar and unfamiliar things that are at hand' (Heidegger, 1993a:170). Everything in the corporation creates a reality; the reward system, the modes of communication, the language used in communication, the architecture, the brands, trademarks, the products, and so on. These are not just features of an entity called 'corporation', rather they are expressions of the 
corporation as it essentially is. Powerful corporations, as powerful works, respond to historical situations and take into full account the environment they find themselves in. They also take into full account the nature of the beings with which they interact; their employees, customers, suppliers, competitors and all kinds of other entities they involve in their world.

\section{Can corporations, as works, pursue efficiency and profit?}

Two important questions arise in testing the understanding of a corporation as a work. Can this understanding be reconciled with such operational requirements as efficiency, effectiveness and flexibility? And, can it be reconciled with the profit motive associated with business? After all a critical feature of business is that it depends fundamentally on its profitability for its sustainability, and generations of experience have demonstrated that many businesses would fail were they not to operate at the cutting edge of skill and technology.

There is, upon consideration, no more difficulty in reconciling the need for technology, operations and management with the understanding of corporation as a work, than there is in understanding the need for technical perfection in the creation of a great symphony, a building or painting. An artist may have great inspiration, but until the inspiration is communicated skilfully using the medium available to the artist - canvas, oils, brushes, technique, style - the inspiration is not a work; it is just an inspiration. Technology is not in conflict with the creative nature of business but an integral, enabling part of it. Both inspiration and technique are necessary to produce a great work. Both creativity and technology are necessary to make a great corporation.

The second of the two questions deals with the issue of value. Many works are acknowledged by people in rather extraordinary ways. Many people pay a significant premium for well-designed fashion, which by far exceeds the amount they would pay just to be covered and warm. People queue for hours, pay large sums of money, and then risk bad weather to be a part of the crowd shouting support for their Wimbledon champions or listening to a rock concert. A service designed not only to fulfil a physical need but also to create identity, make societal statements or express a sense of integrity, can be justified in commanding a significantly higher margin. Corporations themselves are largely valued according to the perception of their ability to be able to generate appropriate margins on their products. While we do not claim that all works can or should be translated into commercial value, an understanding of corporation as a work does not imply that commercial imperatives are ignored. Quite the reverse. J.K. Rowling's Harry Potter novels have been an enormous commercial success, as have Body Shop environmentally responsible cosmetic products, each of which, we suggest, set out to create and sustain a particular kind of world.

In fact, the central argument here is that the more clearly the leaders of corporations understand the true nature of the entities involved in their business the more powerful, sustainable and profitable will be those businesses. In other words, this discussion of the value of a work leads us to strategy. If we accept that a corporation is a work, then the art and science of creating, developing, sustaining and recreating a work must be the essence of corporate strategy.

\section{Corporate strategy as creating and sustaining a work}

Acknowledging the corporation as a work gives us a new starting point for thinking about the task of creating and sustaining a corporation, a task that in business is referred to under terms like management, business leadership or corporate governance. It also gives us a new starting point for strategy as the logic that guides management, business leadership and corporate governance. Once more, though, we begin by discussing the implications of building strategy on a metaphorical understanding of the corporation.

\section{Strategy and metaphors of the corporation}

As noted at the beginning of this paper, Mintzberg et al. have identified ten schools of strategic thought (Mintzberg et al., 1998). In reviewing these schools (design, planning, positioning, entrepreneurial, cognitive, learning, power, cultural, environmental and configuration) it is possible to identify a certain metaphor of the corporation underpinning each of the schools ${ }^{8)}$, and therefore the types of strategy that each school prescribes or describes. It is beyond the scope of this paper to discuss these schools in detail, but we offer some thought on the metaphors as we identify them.

As one might expect, the earlier schools of strategic thought rely on object metaphors for the organisation, suggesting that the organisation can be designed or planned in a predictable fashion. Thus we see that the design school suggests that structure (determined and object-like) must follow strategy, while the planning school relies on what Mintzberg et al. term the fallacy of detachment - 'the system does the thinking' and 'managers must ... manage by remote control' (Mintzberg et al., 1998:72). Similarly, the positioning school, based as it is on military maxims, in which strategy is about the movement of strategic assets around a chessboard-like terrain, clearly conceptualised the organisation as some-thing which can be placed, or moved. Porter (1985) further suggests that the organisation is a value chain (a very dormant metaphor at this point), and strongly orients strategy to the economic and the quantifiable (Mintzberg et al., 1998:112). The organisation is not just an object, but an abstract object - a set of numbers.

The descriptive environmental and configuration schools of strategy use the metaphor of the corporation as an organism, the former relying on contingency and population ecology points of view (Mintzberg et al., 1998), and the latter suggesting an 'organizational eco-cycle' (Mintzberg et al., 1998:323). The learning school goes a step further, and suggests that the corporation is like a human being, having

\footnotetext{
${ }^{8)}$ The entrepreneurial and cognition schools are the exception here, as they do not describe the corporation at all, but focus instead on the strategist.
} 
capacity for learning, emergent sense making, and collective cognition.

The cultural and power schools themselves directly employ the metaphors of the organisation as a political system and the organisation as a culture (Morgan, 1986). Here we would suggest that these metaphors hold a particular status if one understands a corporation to be a work. Heidegger acknowledges the political entity of a state as a work and in this sense corporations can equally be viewed as political entities. Polt points out that 'a world can be interpreted as a culture: that is a system of meanings that makes it possible for a group of people to understand themselves and their environment' (Polt, 1999:137). Considering the corporation as a work means that it is an entity that sets up and produces a world, and thus also produces culture. Therefore the cultural and political dimensions of the corporation are constitutive of the very nature of any work. We believe that these are not merely metaphorical but are ontological statements.

Interestingly Mintzberg et al. (1998) see power and culture as 'factors' rather than essential to the nature of the corporation, or its strategy formation, and in each of these schools retains the human metaphor for the organisation itself. He suggests that these factors need to be overcome, whereas some of the most influential writers on power (Foucault, 1984) and culture (Giddens, 1984) suggest that power, norms and cultural meaning are pervasive and essential constituents of social structure. Perhaps Mintzberg et al. (1998) have been overly reductive in their assessment of these schools.

If each of the schools rely on metaphor, then each school must logically be subject to the limitations of its particular metaphor. We do not suggest that the schools are of no use, anymore than we suggest that metaphors are of no use. Rather, we think that much of what is being offered by the planning school, for example, is to strategy what structural engineering is to architecture ${ }^{9)}$ : critical to success, but not encompassing the very nature of the discipline. Since corporations exist within the constraints of economic, social and environmental viability, a sound microeconomic analysis and understanding of the corporation is critical to corporate strategy. Perhaps each of the strategy schools can assist to some extent in defining the realm of possibilities open to entities interacting with the corporation, even if they do not individually make up all the creative acts of will that are entailed in corporate strategy. To the extent that these schools of thought are not based on an understanding of the very nature of the corporation, they can be seen as supportive disciplines for strategy rather than as strategic thinking itself.

Much of traditional and current strategic thought moves in the domain of finding a technique to produce a certain type of outcome. Techniques make things happen in cause and effect terms. Art makes things happen in an entirely

\footnotetext{
${ }^{9)}$ Readers may note that we are using analogy here, which is a trope, as is a metaphor. In fact we would argue that understanding the corporation as a work makes analogies to other works very powerful but would caution that they apply as do other tropes - only partially (Morgan, 1980)
}

different way. As Heidegger points out: 'The curious fact here is that the work in no way affects hitherto existing beings in the taking effect of a cause. It lies in a change, happening from out of the work, of the unconcealment of beings, and this means of Being' (Heidegger, 1993b:197). What could Heidegger mean? What works do is not manipulate or move things in a physical sense. Works have entities show up in a whole new way. According to Heidegger, powerful works bring forth entities, affirming their very nature in a way that was previously unknown (Heidegger, 1993b). By this interpretation of the nature of a work, it is apparent that none of the strategic schools of thought can, on its own, guide strategy. Nor can they together be sufficient to constitute corporate strategy though each of them can make a contribution and this contribution can be more appropriate and ultimately more powerful within the understanding of the corporation as a work.

\section{Strategy as the creation and sustenance of a work}

If the metaphorical basis of each of the identified schools of thought gives them only partial usefulness, then how might one usefully proceed with corporate strategy? We would suggest that consistent with our identification of the corporation as a work, strategy is the creation and sustenance of the work. This assertion has a number of implications. Strategy as creation cannot privilege thinking over action. Rather, creation must be thinking and action together. The artist cannot think the painting without seeing it; the composer cannot think the music without hearing it. Strategy cannot happen outside of, or remote from the organisation as it is, but must be a process of engagement, and world-creation.

This is where strategy takes on an entirely different role from that which is usually prescribed. Where the organisation is seen as some kind of object (physical, organism, human) situated on the field of a competitive environment, then strategy necessarily becomes a process of positioning and design. The strategy process stands over and above the organisation, operating on it, as a set of manoeuvres, or process of change.

Once, however, we understand that the organisation is a work which worlds, then we cannot confront the organisation, because we are always already in the world which it reveals. Any strategy process can only function within the world, within the referential whole, as a process of working out these references, uncovering the meanings that they give, and understanding how it is that the work hangs together. The strategy process is part of the work itself, and therefore strategy too, works when it worlds. The strategy process must, if it is to work, or world, effectively, be oriented as an ongoing, sustaining, process of making sense of that which we are already in, and that in which we want to be. Therefore, while we offer some suggestions in the following sections about how this approach to strategy might be facilitated, strategy as creation and sustenance of a work cannot be a 'paint by numbers exercise'. Instead we suggest that corporate leaders must grapple with the following questions in order meaningfully to direct their efforts at the creation of a work, which is to interact with the 
entities involved in the corporation and other corporations in a satisfactory, profitable and sustainable way.

\section{What is the world in which you want to be?}

This question asks about the work in an indirect way. It does not ask about the organisation itself, but about the world it will reveal. This is not the same as asking 'what is our vision', unless one were to understand 'vision' as the implication of everything that the organisation sets up, shapes and shares. This question does take corporate strategy back to a place in which it has to take cognisance of the role of corporations in society, and the entities that will interact with or be impacted upon by the corporation. It takes business leaders back to the place where they identify the fundamental truths that they want to express through the existence of their corporation. This could result in a deeply satisfying re-examination of the impact that business leaders would like to have on the many worlds they impact through their activities. However, it is not a questioning for the sake of such satisfaction. It is a question that needs to be asked because the organisation will always reveal a particular world. By questioning that world, we can work out the work, as it were, and uncover the organisation as it really is, and as it can be.

This is not an idealistic questioning. We are not saying that strategy can 'change the world'. We are saying that strategy can mould the work that reveals a world. This is also not a questioning that conflicts with profitability. Quite the opposite, it is the identification with the same deep truths experienced by customers, suppliers, employees, and future generations of stakeholders that ultimately establishes the robust position of a corporate in their minds, thereby creating the conditions essential to the success of the corporate. The actions of employees of Royal Dutch/Shell in reformulating their corporate values since their Brent Spar and Nigerian public relations disasters (The Economist, 1997) bear testimony to the costs that can be incurred when the world the corporation is happy to create is out of touch with the world that would most satisfy other affected entities. It is also testimony to the fact that a process of 'recreation' based on a redefinition of the fundamental principles to which the corporate leadership aspires can, over time, restore the standing of the corporation in the minds of stakeholders.

\section{What will be allowable within that world?}

Having established the key elements of the world which the corporation would reveal, the focus of strategy formulation moves to a definition of the activities that are and are not consistent with establishing that world. The possibilities for action available to corporations is unlimited, and many of the activities are consistent with the essential nature of the world that the leadership of the corporation would like to communicate. Some are not. The realm of possibilities available to the artist is defined both by the essential content that is to be communicated in the work, and by the technical limitations imposed by the medium through which the work is to be communicated. If a novel is to be believable, the protagonists cannot act entirely out of character.
This contribution to the formulation of strategy is surprisingly profound. The challenge facing business leaders in the world is increasingly to be found in the plethora of options available to them for corporate activities, rather than in the dearth of those opportunities. Each of many different schools of though will present different possibilities. A key strategic responsibility is taken by leaders who define which of those activities is fundamentally inconsistent with the world they want to establish, and who therefore eliminate activities that could be ruinous. If, for example, leaders acknowledge that their stakeholders are fundamentally oriented towards honest, fair dealings, then they would elect not to inflate corporate profitability for the sake of those stakeholders, even when the regulatory framework dealing with the specific issues at stake is silent or unclear ${ }^{10)}$.

Business leaders will then find themselves operating under self imposed constraints - sometimes apparently to their own detriment if their competitors do not perceive those constraints to be necessary - and yet it is these constraints that make of their corporations entities to which their customers are drawn. Body Shop cosmetic products appeal to a broad base of customers on exactly this feature of their identity - the fact that they choose not to violate a number of self-imposed operating constraints, such as opposing animal testing and supporting fair trade.

\section{What are the practices that will sustain the corporation as a work that reveals the world in which we want to be?}

Establishing practices consistent with the objectives and principles of the corporation is much like establishing the character of a protagonist in a novel through the quirks of his or her actions and words, repeated under a range of different circumstances. The practice of reporting detailed information on the environmental impact of operations supports Anglo American plc, through the scrutiny of civil society observers, to operate in accordance with its sustainable development principles. The process of engaging and listening to the views of a diverse range of stakeholders ensures that Royal Dutch/Shell employees align themselves with broadly acceptable corporate values (The Economist, 1997). Redefining the time period over which asset managers' performance is measured - a small change in the motivational process - could have profound impact on the nature of the asset management company. Practices suggested by Mintzberg et al. (1998) could be incorporated into corporate activity, providing they are not inconsistent with the work the corporate leaders want to set up, shape and share.

\section{Conclusion}

It should be evident that asking these questions as the central part of a strategy process or conference is very valuable, but that these questions cannot be confined to such discrete occasions. Setting up, shaping and sharing a work in

\footnotetext{
${ }^{10)} \mathrm{A}$ particular strength of the understanding of corporation as work is revealed here. If the realm of possiblities available to the corporation were to be defined on the basis of prevailing metaphors, it is apparent that the result could be different for every fundamentally different metaphor.
} 
a particular way will require that these questions are asked and answered constantly, and across all levels of the corporation. Other strategy techniques may well be incorporated into the process of addressing these questions, though it should be apparent that it is not possible to reduce corporate strategy to a foolproof recipe. The very idea of a corporation as a work precludes such a possibility. There is no sure way of producing extraordinary works, and there is no sure way of creating remarkable corporations. A work is something that is created, by individuals or groups of individuals, who in so doing express an inspiration and create a very world.

We propose that every corporation is necessarily a work - it always creates a world - even if the work sets up and shapes a world that is not one with universal or even broad appeal. For many people, the corporation does indeed appear as a faceless machine, or an iron cage. Understanding the corporation as a work that sets up and shapes the world for many people implies a creative adventure - full of uncertainties, challenges and surprises - and one in which there is no guarantee of success or sustainability. It also implies that it is the kind of world that the corporation creates that we are at liberty to determine.

We propose that business leaders and managers are more likely to conduct themselves in a manner consistent with the remarkable responsibility invested in them when they understand the nature of the task of creating and sustaining corporations. Such an understanding leads to a realisation that their words and actions define the realm of possibility for action for many of their stakeholders, and that only in identifying with the deep human values of those stakeholders can they establish a sure foundation of achieving sustainable success.

\section{References}

Astley, W. G. 1984. 'Toward an appreciation of collective strategy', Academy of Management Review, 9:526-535.

Beer, M. 1980. Organization change and development. Santa Monica: Goodyear.

De Geus, A. 1997. 'The living company' Harvard Business Review, March-April pp.51-59.

Economist, The. 8 May 1997. 'Shellman says sorry'.

Economist, The. 12 April 2001 'Battle of the platforms'.

Economist, The, 20 December 2001. 'The future of the company: a matter of choice'.

Economist, The 1 November 2001, 'Will the corporation survive'.

Fairclough, N. 1995. Critical discourse analysis. London: Longman.

Fayol, H. 1949. General and industrial management. London: Pitman.
Foucault, M. 1984. In Rabinow, P. (Ed.). The Foucault reader: An introduction to Foucault's thought. London: Penguin Books, pp. 51-75.

Fowler, H. W. \& Fowler, F. G. (Eds.) 1964. The concise Oxford dictionary of current English. Oxford: Oxford University Press.

Giddens, A. 1984. The constitution of society: Outline of the theory of structuration. Oxford: Blackwell.

Grant, D., Keenoy, T. \& Oswick, C. (Eds.) 1998. Discourse and organization. London: Sage.

Hannan, M. J. \& Freeman, J. H. 1977. 'The population ecology of organizations' American Journal of Sociology, 82: 929-964.

Heidegger, M. 1962. Being and time. Oxford: Basil Blackwell.

Heidegger, M. 1993a. Basic writings. San Francisco: Harper Collins.

Heidegger, M. 1993b. In Heidegger, M. Basic writings. San Francisco: Harper Collins, pp. 143-212.

Jones, M. 1995. 'Organisational learning: Collective mind or cognitivist metaphor?' Accounting, Management and Information Technologies, 5, 61-77.

Kast, F. E. \& Rosenzweig, J. E. 1973. Contingency views of organization and management. Chicago: Science Research Associates.

Katz, D. \& Kahn, R. L. 1978. The social psychology of organizations. New York: John Wiley.

Luhmann, N. 1995. Social systems. Stanford: Stanford University Press.

Mintzberg 1987. 'The Strategy Concept 1: Five Ps for Strategy', California Management Review, 30, 11-24.

Mintzberg, H., Ahlstrand, B. \& Lampel, J. 1998. Strategy safari: A guided tour through the wilds of strategic management. London: Prentice Hall.

Morgan, G. 1980. 'Paradigms, metaphors and puzzle solving in organization theory', Administrative Science Quarterly, 25, 605-622.

Morgan, G. 1983. 'More on metaphor: Why we cannot control tropes in organization theory', Administrative Science Quarterly, 28, 601-607.

Morgan, G. 1986. Images of organization. London: Sage. First Edition.

Pinder, C. C. \& Bourgeois, V. W. 1982. 'Controlling tropes in administratrive science', Administrative Science Quarterly, 27, 641-652. 
Polanyi, M. 1969. Knowing and being. London: Routledge.

Polt, R. 1999. Heidegger: An introduction. Ithaca, New York: Cornell University Press.

Porter, M. E. 1985. Competitive advantage: Creating and sustaining superior performance. New York: The Free Press.

Senge, P. 1990. The fifth discipline: The art \& practice of the learning organization. New York: Doubleday.

Stacey, R. 1992. Managing chaos: Dynamic business strategies in an unpredictable world. London: Kogan Page.

Taylor, F. W. 1911. Principles of scientific management. New York: Harper \& Row.

Tsoukas, H. 1991. 'The missing link: A transformational view of metaphors in organizational science', Academy of Management Review, 16, 566-585.

Ulrich, H. \& Probst, G. J. B. (Eds.). 1984. Self-organization and management of social systems. New York: SpringerVerlag.

Van Dijk, T. A. (Ed.). 1997. Discourse as structure and process. London: Sage.

Von Grogh, G. \& Roos, J. 1995. Organizational epistemology. New York: St Martin's Press.

Weber, M. 1978. Economy and society. Berkeley, CA: University of California Press.

Wheatley, M. J. 1992. Leadership and the new science. San Francisco: Berrett-Koehler. 